\title{
PROTOTYPING A RETROSPECTIVE REVIEW SUPPORT FUNCTION FOR A FILL-IN WORKBOOK SYSTEM
}

\author{
Kousuke Abe ${ }^{1}$, Tetsuo Tanaka ${ }^{2}$ and Kazunori Matsumoto ${ }^{2}$ \\ ${ }^{1}$ Course of Information and Computer Sciences, Graduate School of Engineering, Kanagawa Institute of Technology \\ ${ }^{2}$ Dept. of Information and Computer Sciences, Faculty of Information Technology, Kanagawa Institute of Technology \\ 1030 Shimo-ogino, Atsugi, Kanagawa, 243-0292, Japan
}

\begin{abstract}
The authors are developing and using a fill-in workbook system that allows faculty members to ascertain the attitude of all students to classes including students who are not active, and to improve lectures through well-timed and appropriate actions. In this paper, in order to help teachers improve lessons and teaching materials, and to help students review their own learning attitude, we propose functions for retrospective review. We focus on unfocused time, page transitions, number of keyboard operations and number of mouse clicks to extract the learning attitude of each student during the class. This function divides student's learning attitude into five categories, i.e. following the class and concentrated on it, following but not concentrated, jumping ahead, falling behind, and not participating. The system also provides visualization of changes in learning attitude during the class. It can be used for teacher's and students' retrospective review after the lecture.
\end{abstract}

\section{KEYWORDS}

Lecture Support, Fill-In Blanks, Learning Attitude, Log Analysis, Learning Analytics

\section{INTRODUCTION}

The computerization of higher education is progressing in, for example, the spread of LMSs (Learning Management Systems), which manage lecture materials and student reports on the Internet. In conjunction with this, learning analytics, which analyzes operation logs in LMSs and e-learning systems, is attracting attention. Learning analytics involves collecting a log of the learning process, to identify items such as which part of the material the student is learning, and when and for how long the student is learning. Analyzing this can contribute to class improvement and the provision of learning support(Ferguson, 2012, Kumar, 2018, Viberg, 2018, Diana, 2019, Verbert, 2020). Particularly in recent years, a real-time learning analysis environment that supports teachers and students in classrooms has been made possible by the development of wireless LANs in classrooms and the practice of "bring your own device" (BYOD), in which students bring their own laptops and other devices into the classroom (Shimada, 2018, Shimada, 2017, Fu, 2017).

The operation logs used in learning analytics mainly contain data on time and content such as turning the pages of teaching materials, underlines, memos, and questions. Therefore, it is possible to ascertain the status of engaged learners who actively underline, take notes, or ask questions. However, it is difficult to ascertain the status of many other students who attend classes but do not participate actively in learning.

Based on this background, the authors are developing a fill-in workbook system that will both allow faculty to ascertain the learning attitudes of all students, including those who are not active, and improve lectures through well-timed and appropriate actions, and also help students to understand lectures in an efficient manner. In a class using this system, students are provided with materials containing blanks to be filled in, and they engage in the lesson while filling the blanks in the materials. The operation logs are collected and analyzed and teachers and students receive feedback. This system compels students in class to interact with the system and makes it possible to collect the learning activities of students who are not active in class.

The authors have already reported on the function and configuration of the system (Abe, 2018), and the results of a trial using the system in a small class. A trial of about 90 students engaged in one lesson and extraction of class attitudes and the degree of understanding from system logs were reported in (Abe, 2019). 
In (Abe, 2020), we reported the results of using this system continuously over multiple lessons of a single course.

On the basis of the results of the analysis so far, and in order to help teachers improve lessons and teaching materials and to help students review their own learning attitude, in this paper we propose specific functions for retrospective review. In Section 2, we summarize the operation logs and analysis target. Section 3 describes a method of extracting changes in each student's learning attitude for each lesson and for each time interval / each slide in the lesson for the entire class. Prototype retrospective review support functions are described Section 4 .

\section{ANALYSIS TARGET}

In this study, in order to collect the learning behavior logs, we use a fill-in workbook system that the authors are developing. Before a lesson using this system, teachers create teaching materials by uploading PDF documents to which blanks are added in important sentences. In the lesson, teachers peel off the blank revealing the answer with the relevant explanations.

Students fill in the blanks while referring to these materials in a screen like that shown in Figure 1. The blanks filled with correct answer are opened. The operation logs are recorded in the database. In the teacher's screen (see example Figure 2) the results of analyzing the operation logs and extracting the learning attitudes are shown visually and presented to the teacher in real time.

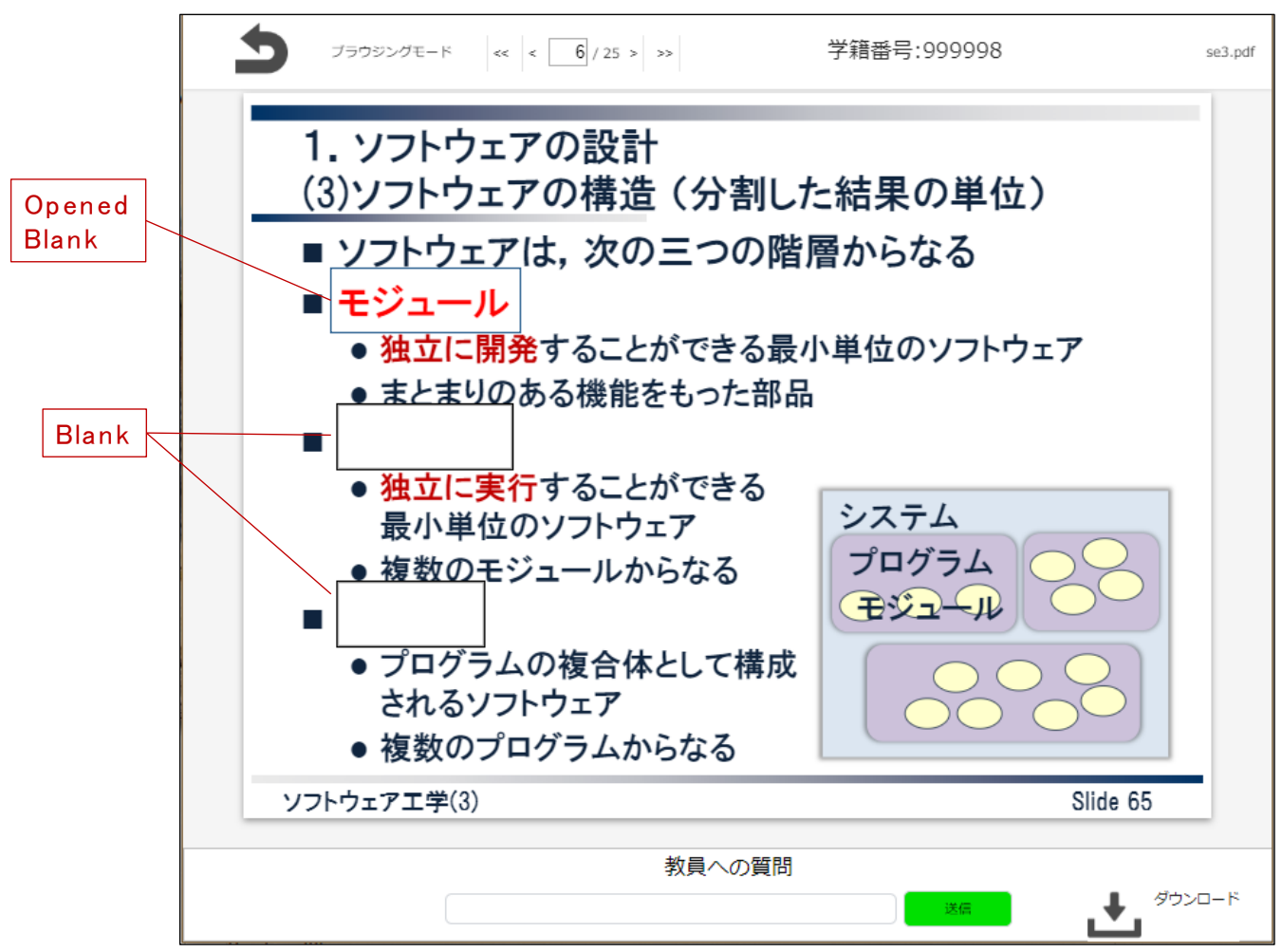

Figure 1. Example of student's screen 


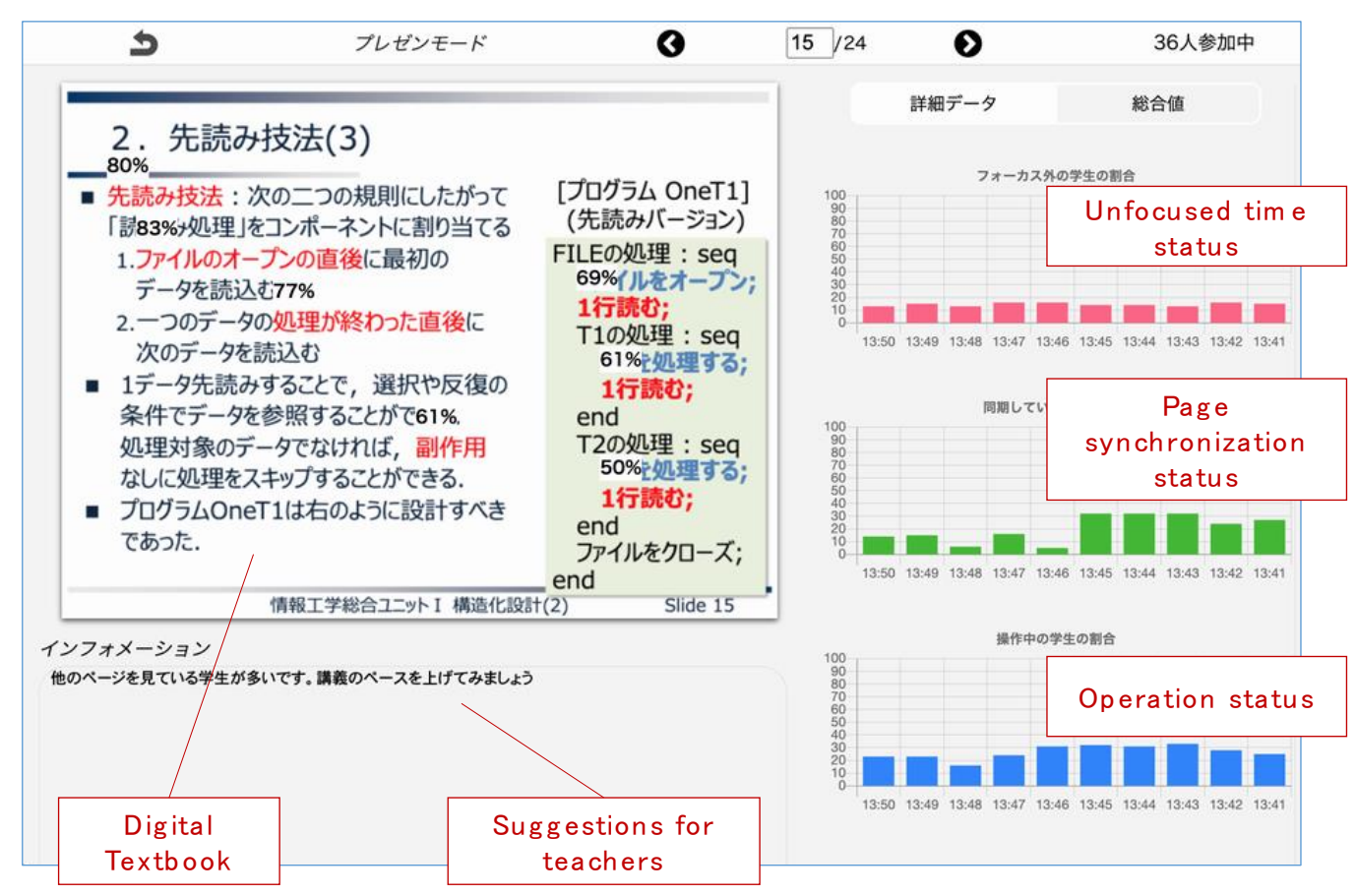

Figure 2. Example of teacher's screen

By using the system, students are compelled to interact with the system, and the operation logs of inactive students (students who do not actively participate in learning activities by, for example, underlining and writing notes) can be acquired. If teachers can effectively assess the student's learning attitude in real time during class, they can then take actions that encourage students to concentrate whenever the number of students with a poor learning attitude is seen to increase.

The items in the operation logs collected using this system are as follows:

- Fill-in blanks: Content and time of each answer written in the blank space, and whether answers are correct or incorrect

- Underlining: Underline position

- $\quad$ Notes: Note position and content

- Operation logs: Page focus time, number of mouse operations, number of keyboard operations per minute

- $\quad$ Page turning details: Time and destination page numbers

- Question details: Content of questions asked by students during class

In addition, a log of the teacher's operations is also compiled and can be used to compare course progress with the student's operation log. The teacher's operation log includes the following items:

- $\quad$ Page turning details: Time and destination page numbers

- $\quad$ Blanks peeled off (displaying correct answer): Peel-off times and identifiers of blanks peeled off

In analyzing the results of this study, we focused on the degree of synchronization between the teacher's slide transition and the student's slide transition, the number of keystrokes and mouse clicks, and unfocused time that is the time during which the student does not focus on the system - as collected by the learning behavior log as an indicator of overall class attitude.

The analysis was based on data collected during 90 minutes of actual lectures conducted by one faculty as follows:

- $\quad$ Software Engineering

subject related to software development methods

90 students from the Department of Information and Computer Sciences 2nd grade 
- Introduction to Software subject related to algorithms and data structures

130 students from the Department of Information and Computer Sciences 1st grade

\section{METHOD OF EXTRACTING LEARNING ATTITUDES}

In order to support the teacher's and the student's review of the class, changes in the attitude of each student during the class are extracted. We focus on unfocused time, page transitions, number of keyboard operations and number of mouse clicks to extract the attitude of each student during the class as follows:

- A student who is synchronized with the teacher's page transition most of the time and there is no unfocused time is considered to be attentive. unfocused time is the time during which the student does not focus on the system, for example, a student is opening another application such as to check email.

- $\quad$ The reference page may be synchronized with the teacher's explanation even in a time period with many unfocused periods. In addition, keyboard operations are also being performed a short time after page transition. The student at this time seems to be in a state of looking at the material without listening to the teacher's explanation, and filling in the blanks on the page while looking at the teacher's presentation material immediately after turning the page.

- Students jumping ahead are not listening to the teacher's explanation, that is, their learning attitude can be regarded as bad.

- Students falling behind can also be considered as not being able to keep up with the pace of the lecture, or sleeping or doing other things and not listening to the teacher's explanation. These can be distinguished by the presence or absence of operations.

- There may be a time period during which there is no page transition or operation for an extended period. During this time, the pages being explained by the teacher contain blanks, so it is necessary to fill in the gaps, but there are no operations and no page transition. It can be assumed that during this time the student is doing other things or sleeping without paying attention to the lecture.

To summarize the above, students' learning attitudes can be divided into the five categories shown in Table 1 based on unfocused time, page transitions, keyboard operations, and mouse clicks.

Table 1. Correspondence between operation log and learning attitude

\begin{tabular}{|c|c|c|c|c|}
\hline & Learning Attitude & Unfocused time & $\begin{array}{l}\text { Keystroke, } \\
\text { Mouse click }\end{array}$ & Page transition \\
\hline 1.Excellen 1 & $\begin{array}{l}\text { Following and } \\
\text { concentrated }\end{array}$ & $\begin{array}{l}\text { Less than } 30 \text { seconds } \\
\text { per minute }\end{array}$ & - & Synchronized \\
\hline 2.Good & $\begin{array}{l}\text { Following but not } \\
\text { concentrated }\end{array}$ & $\begin{array}{l}30 \text { seconds or more } \\
\text { per minute }\end{array}$ & - & Synchronized \\
\hline 3.Fair & Jumping ahead & - & - & Jumping ahead \\
\hline 4.Poor & Falling behind & - & Yes & Falling behind \\
\hline 5.Bad & Not participating & - & No & Falling behind \\
\hline
\end{tabular}

\section{RETROSPECTIVE REVIEW FUNCTION}

\subsection{Function for Students}

By presenting the transition of learning attitude to the students in the form of a retrospective review after the lecture, they can be made aware of the problems during the lecture and become more conscious of their learning attitude. We prototyped the retrospective review function.

Figure 3 shows an example of the retrospective review screen. The horizontal axis is the time from the start of the lesson, measured every minute. The bar graph at the top shows the unfocused time; the green line graph is the page being explained by the teacher, and the gray line graph is the page being referenced by the student. The left vertical axis corresponds to a line graph with page numbers, and the right vertical axis corresponds to a 
bar graph showing unfocused time (seconds). The middle part of Figure 3 is a line graph showing the learning attitude. The bottom bar graph shows the total number of mouse clicks and keyboard operations per minute.

This allows students to look back on their class attitude after class. For example, the students can find out in which part of the lesson they could not keep up with the teacher's explanation, or if they had a lapse in concentration. Thereby they can focus on reviewing that part, or ask other students/teachers about that part.

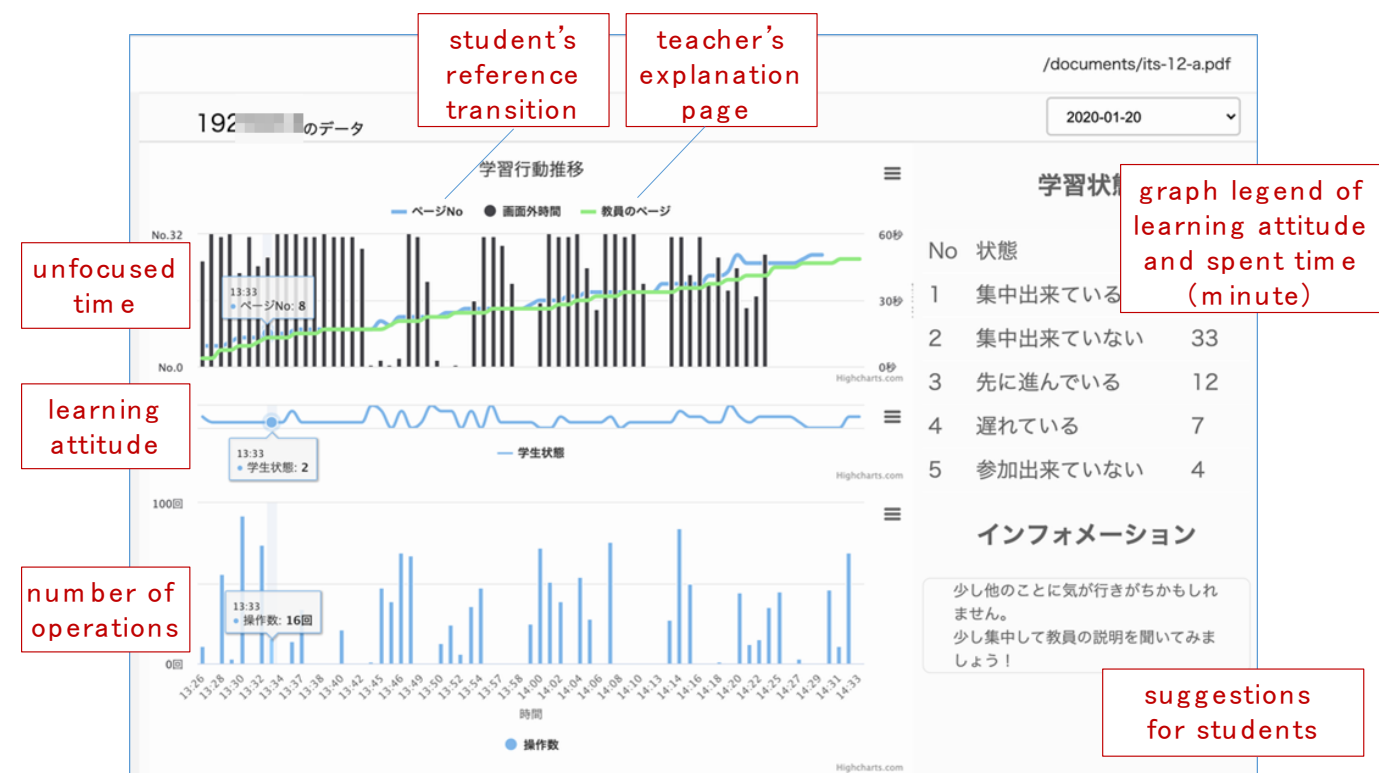

Figure 3. Example of retrospective review screen for students

\subsection{Function for Teachers}

This system provides the function of creating a time sequence aggregate learning attitude chart by totaling the learning attitudes of all students described in the previous section, and the function of presenting it to the teacher. This will allow teachers to improve their lessons. For example, if many students are late in class, the teacher can slow down the class or explain the material in more detail. After class, the teacher can improve teaching materials during the time when many students are late. In addition, individual guidance can be given such as selecting students who tend to be late and giving them advice.

Figure 4 shows a review screen for teachers. The horizontal axis is time. The upper bar graph shows the ratio of the five learning states at each time. This allows the teachers to understand how the student's learning status is changing. The lower bar graph shows the value of the learning attitude index (LAindex) expressed by the following formula at each time.

$$
\begin{aligned}
& \text { LAindex }=\frac{\left(L A_{2}+2 L A_{3}+3 L A_{4}+4 L A_{5}\right)}{4 N} \times 100 \\
& L A_{i}: \text { number of students of status } i \text { in Table } 1
\end{aligned}
$$

\section{$\mathrm{N}$ : number of students}

Furthermore, the points where the LA index sharply rises are displayed in yellow, and the points where the high LA index continues are displayed in pink. These are the points that teachers should pay attention to. 


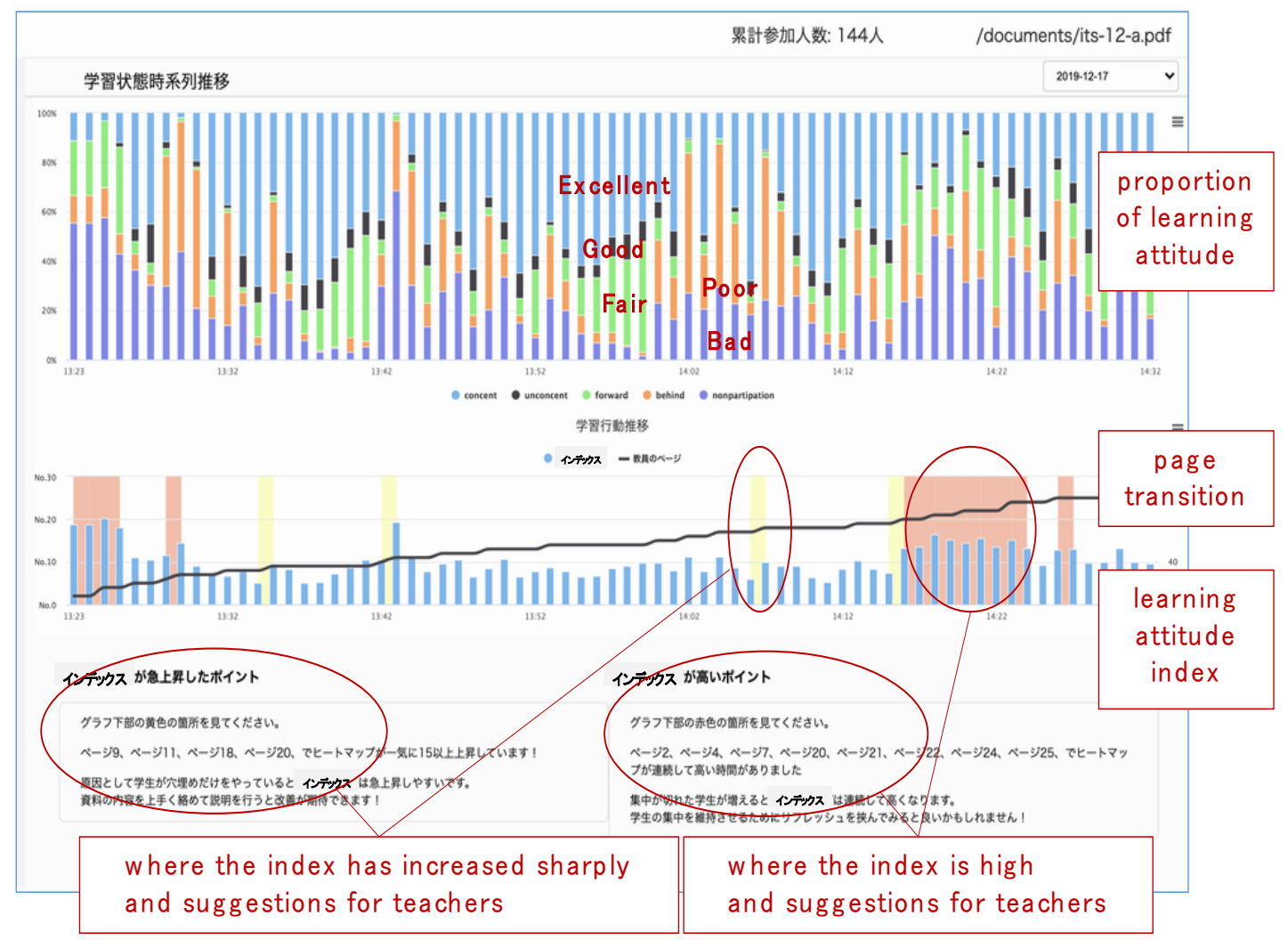

Figure 4. Example of retrospective review screen for teachers

\section{CONCLUSION}

In order to help teachers improve lessons and teaching materials, and to help students review their own learning attitude, we propose functions for retrospective review. We focus on unfocused time, page transitions, number of keyboard operations and number of mouse clicks to extract the learning attitude of each student in the class. This function divides student's learning attitude into five categories: following the class and concentrated; following but not concentrated; jumping ahead; falling behind; and not participating. It also visualizes changes in learning attitude during the class. It can be used for the teacher's and the students' retrospective review after the lecture.

The verification of the validity of the relationship between the operation log and the learning attitude is a future task. The learning attitude judged from the operation log will be presented to the students, and it will be verified by questionnaire whether or not they agree with the students' own senses. Furthermore, the results will be compared with the results of the method of estimating class attitudes proposed in other studies.

\section{ACKNOWLEDGMENT}

This work was supported by JSPS KAKENHI Grant Number JP20K03078. 


\section{REFERENCES}

Abe, K. et al, 2018. Lecture Support System using Digital Textbook for Filling in Blanks to Visualize Student Learning Behavior, In International Journal of Education and Learning Systems, Vol.3, pp. 138-144.

Abe, K. et al, 2019. Analysis of Learning Behavior Logs based on a Fill-in Workbook System - Toward Real-time Learning Analytics -, In International Journal of Education and Information Technologies, Vol. 13, 2019, pp. 154-159.

Abe, K. et al, 2020. Learning Attitude Analysis based on Operation Log of Fill-in Workbook System, Proceedings of IIAI 9th International Congress on Advanced Applied Informatics, Online, to appear.

Diana, M. et al, 2019. A Visual Dashboard to Track Learning Analytics for Educational Cloud Computing, In Sensors, 19.

Ferguson, R., 2012. Learning analytics: drivers, developments and challenges. In International Journal of Technology Enhanced Learning, 4(5/6) pp. 304-317.

$\mathrm{Fu}, \mathrm{X}$. et al, 2017. Real-time learning analytics for C programming language courses, Proceedings of the Seventh International Learning Analytics \& Knowledge (LAK '17), Vancouver in Canada, pp. 280-288.

Kumar, K. and Vivekanandan, V., 2018. Advancing learning through smart learning analytics: a review of case studies, In Asian Association of Open Universities Journal, Vol. 13 No. 1, pp. 1-12.

Shimada, A. and Konomi, A., 2017. A Lecture Supporting System Based on Real-time Learning Analytics, Proceedings of CELDA2017, Vilamoura, Algarve, Portugal, pp. 197-204.

Shimada, A. et al, 2018. Real-time learning analytics system for improvement of on-site lectures, In Interactive Technology and Smart Education, Vol.15, No. 4, pp. 314-331.

Verbert, K. et al, 2020. Learning analytics dashboards: the past, the present and the future, Proceedings of the Tenth International Conference on Learning Analytics \& Knowledge (LAK'20), Cyberspace, pp. 35-40.

Viberg, O. et al, 2018. The current landscape of learning analytics in higher education, In Computers in Human Behavior 89, pp. 98-110. 